\title{
Trends of Co-Morbid Depression in Hospitalized Patients with Failed Back Surgery Syndrome: An Analysis of the Nationwide Inpatient Sample
}

\author{
Vwaire Orhurhu · Ivan Urits · Mayowa Olusunmade - Khurram Owais • \\ Mark Jones · Annemarie Galasso • Mariam Salisu Orhurhu • \\ Issa Mohammed
}

Received: July 30, 2018 / Published online: September 14, 2018

(C) The Author(s) 2018

\section{ABSTRACT}

Introduction: Co-morbid depression has been associated with poor outcomes following spine surgery and worsening of low back pain symptoms leading to failed back surgery syndrome (FBSS). Given the increasing focus of healthcare utilization and value-based care, it is essential to understand the demographic and economic

Enhanced digital features To view enhanced digital features for this article go to https://doi.org/10.6084/ m9.figshare.6974486.

V. Orhurhu $(\bowtie) \cdot$ I. Urits · K. Owais · M. Jones Department of Anesthesiology, Critical Care and Pain Medicine, Beth Israel Deaconess Medical Center, Harvard Medical School, Boston, MA, USA e-mail:vwo569@mail.harvard.edu

M. Olusunmade

Department of Psychiatry, Rutgers New Jersey

Medical School, Newark, NJ, USA

\section{A. Galasso}

Georgetown University Medical School, Medstar Georgetown University Hospital, Washington, DC, USA

M. Salisu Orhurhu

Departments of Anesthesiology and Critical Care Medicine, Johns Hopkins School of Medicine,

Baltimore, MD, USA

I. Mohammed

Department of Psychiatry, Anesthesia and Pain

Management, Harvard Medical School, Brigham and

Women's Hospital, Boston, MA, USA data surrounding co-morbid depression amongst patients with FBSS.

Methods: Our study investigated the NIS database for FBSS patients who had co-morbid depression (ICD-9 CM codes 300.4, 301.12, 309.0, 309.1, 311; ICD-10 M96.1) between 2011 and 2015 across 44 states. We obtained demographic and economic data such as age, sex, ethnicity, location, number of in-patient procedures, hospital length of stay, cost of hospital stay, and frequency of routine discharge dispositions. The NIS database represents approximately a $20 \%$ sample of discharges from hospitals in the United States. These data are weighted to provide national estimates for the total United States population. National administrative databases (NADs) like National Inpatient Sample (NIS) are a common source of data for spine procedures. This database is appealing to investigators because of ease of data access and large patient sample. The NIS database is a de-identified database that consists of a collection of billing and diagnostic codes used by participating hospitals with the goal of quality control, population monitoring, and tracking procedures. The NIS does not require institutional review board (IRB) approval or exempt determination.

Results: Between 2011 and 2015, a total number of 115,976 patients with FBSS were identified. Of these patients, about 23,425 had comorbid depression. The rate of co-morbid depression in 2015 was $23 \%$ with the lowest 
reported rate being 20\% in 2011. Females and Caucasians had consistently higher rates of comorbid depression compared to males and other ethnic groups respectively. The average length of stay for patients with co-morbid depression fluctuated between 2011 and 2015, with the highest reported at 4.81 days in 2015 . The number of procedures increased steadily from 2011 to 2015 with a dip in 2013. The highest number of procedures was reported as 3.94 in 2015. The mean total hospital charges remained stable over time with the largest change being the decrease from 2011 (mean $\$ 93,939 ; 95 \%$ CI $\$ 80,064-\$ 107,815)$ to 2012 (mean 82,603; 95\% CI \$75,127-\$90,079). Additionally, patients with FBSS and co-morbid depression were more often discharged home than home with healthcare or to another healthcare facility.

Conclusions: The occurrence of co-morbid depression in hospitalized patients with FBSS increased from 20\% in 2011 to $23 \%$ in 2015. While direct hospital costs and length of stay remained relatively stable, the number of inpatient procedures performed trended upwards. The exact etiology for this increase in depression prevalence is unknown; additional studies are needed to shed further insight.

Keywords: Chronic pain; Chronic regional pain syndrome; Depression; Failed back surgery syndrome; Healthcare utilization; Spinal stenosis; Total cost

\section{INTRODUCTION}

Low back pain is one of the most common health complaints in the global population. Worldwide, it is estimated to have a lifetime prevalence of $60-80 \%$, with symptoms lasting for longer than 3 months in 10\% of individuals $[1,2]$. In the United States, the total number of adults living with low back pain is over 12 million, causing disability in $50 \%$ of instances $[3,4]$. Though conservative management is often effective in the management of low back pain, surgical treatment is frequently pursued for patients who remain severely symptomatic. In line with a growing population of chronic back pain sufferers, the yearly incidence of lumbar fusion surgery performed in the United States between the years 1998 and 2008 increased from 77,682 to 210,407 . In 2002 alone, the total number of spinal surgeries exceeded 1 million $[5,6]$. Despite undergoing technically adequate surgery to address the presumed pathology, many patients continue to have chronic, disabling low back pain [7]. This translates to a significant incidence of failed back surgery (FBSS), demonstrated to range from a rate of $10-40 \%$, and estimated to affect 80,000 Americans yearly [8].

The persistence of pain after spine surgery is described as FBSS. It was first defined by Follett, as surgical end stage after one or several operative interventions, indicated to relieve lower back or radicular pain, both without positive effect [9]. FBSS can be assigned a specific diagnosis in $95 \%$ of instances and consists of various etiologies, which include spinal stenosis, internal disc disruption, recurrent disc herniation, and neural fibrosis [7]. Despite this, subsequent surgeries performed have diminishing rates of success [10]. Ultimately, this leads to increased patient pain and lower quality of life, akin to chronic pain conditions such as rheumatoid arthritis, complex regional pain syndrome, and fibromyalgia [11].

Patients with depression are associated with poorer surgical outcome, worsening of symptoms, and refractory low back pain leading to FBSS [12]. Data pertaining to prevalence of depression in patients with FBSS have been previously reported in outpatient settings [11]. In this study, we perform an analysis of an inpatient sample and discuss the rate of comorbid depression in FBSS and its association with healthcare utilization amongst hospitalized patients.

\section{METHODS}

\section{Database Characteristics}

NIS data from 2011 to 2015 was reviewed and included in our analysis. The NIS is one of the Healthcare Cost and Utilization Projects databases that is sponsored by the Agency for 
Healthcare Research and Quality [13]. This database is considered the largest all-payer inpatient care database in the US, which has been used in multiple instances to analyze national trends in outcomes, quality, charges, access and health care utilization, based on data extracted from 7 to 8 million hospital stays. These hospital stays represent approximately $20 \%$ of US community hospitals, defined as all academic medical centers, general specialty hospitals, non-federal, and short-term medical centers. In our analysis, we included chemical dependency treatment facilities, long-term acute-care hospitals, psychiatric hospitals, and short-term rehabilitation facilities. For this study, we considered hospitals from 46 states that contributed discharge information to the NIS database. Hospitals within a given stratum have similar statistical probability of sample selection regardless of appearance in prior sample. Further information on the design and statistical information of the NIS is available at http://www.hcup-us.ahrq.gov.

\section{Inclusion and Exclusion Criteria}

Our study evaluated patient information data acquired from NIS, from 2011 to 2015, to determine the trends of co-morbid depression in patients with FBSS. We included all patients with the diagnosis of depression and FBSS in our analysis. The ICD-9 CM codes for patients who had co-morbid depression were listed as 300.4, 301.12, 309.0, 309.1, and 311 for 2011 through 2015. Similarly, patients with a diagnosis of FBSS were listed to have an ICD-9 code of $722.80,722.81,722.82$, and 722.83 as well as ICD-10 code of M96.1 (for Q4 2015). Patients without a diagnosis of FBSS were excluded from our analysis.

\section{Variables and Outcomes}

For all FBSS patients with a diagnosis of comorbid depression from 2011 to 2015, we analyzed patient demographic variables like age, sex, and race. Health care utilization outcomes including hospital charges, length of hospital stay, number of inpatient procedures, and discharge dispositions were also included in our analysis. The appropriate weights from the NIS database were applied to obtain national estimates. Charges were adjusted for inflation using CPI estimates from the Bureau of Labor Statistics and are reported in 2015 US dollars.

\section{Statistical Analysis}

Our NIS database was de-identified, thereby exempting it from our institutional review board. We performed a two-sample Student's $t$ test to analyze the difference in continuous variables. Categorical variables were analyzed with Chi-square or Fisher's exact test. $p$ values $<0.05$ were considered statistically significant. We conducted our analysis using STATA 14 (StataCorp. 2016. Stata: Release 12, Statistical Software. College Station, TX: StataCorp LP).

\section{COMPLIANCE WITH ETHICAL GUIDELINES}

National administrative databases (NADs) like NIS [14] are a common source of data for spine procedures [15]. This database is appealing to investigators because of ease of data access and large patient sample. The NIS database is a deidentified database that consists of a collection of billing and diagnostic codes used by participating hospitals with the goal of quality control, population monitoring, and tracking procedures. The NIS does not require institutional review board (IRB) approval or exempt determination. These diagnostic and procedure codes are designated at the discretion of physicians or hospital billing department rather than by defined clinical or radiographic diagnostic criteria. The NIS dataset does not directly involve "human subjects" as defined by federal regulations and guidance (https://www.hhs. gov/ohrp/regulations-and-policy/regulations/ common-rule/index.html). Thus, all procedures performed were in accordance with the ethical standards of the institutional and/or national research committee and with the 1964 Helsinki Declaration and its later amendments or comparable ethical standards. 


\section{RESULTS}

Between 2011 and 2015, a total number of 115,976 patients with FBSS were identified. Of these patients, about 23,425 had reported comorbid depression during their inpatient hospital stay. Patients with failed back surgery syndrome were mostly females (mean proportion 52.06, 95\% CI 51.3-52.8) with the majority of patients located at an urban location (mean proportion 94.1, 95\% CI 92.8-95.2) (Table 1). In addition, our study population consisted of patients within ages 45-64 years old and a predominantly white ethnic group (Table 1 ).

\section{Overall Trends of Co-morbid Depression}

The annual total number of patients with depression fluctuated each year but was relatively stable between years 2012 and 2014 (Fig. 1). The highest prevalence of co-morbid depression in patients with FBSS was recorded in 2015 as $23 \%$ while the lowest number of patients with depression was recorded as $20 \%$ in 2011. The most dramatic increase in prevalence of co-morbid depression in patients with FBSS over a single year was recorded as $1.7 \%$ from 2014 to 2015 . Although not statistically significant, the prevalence of co-morbid depression in this population consistently trended upwards throughout the period of the analysis $(p=0.149)$ (Fig. 1).

Table 1 Demographic summary of all patients with failed back surgery

\begin{tabular}{|c|c|c|c|}
\hline & \multirow[t]{2}{*}{ All patients with FBSS } & \multicolumn{2}{|c|}{ Co-morbid depression } \\
\hline & & $\overline{\text { No }}$ & Yes \\
\hline \multicolumn{4}{|l|}{ Gender } \\
\hline Male & $47.94(47.2-48.7)$ & $42.51(42.4-42.6)$ & $36.78(35.3-38.3)$ \\
\hline Female & $52.06(51.3-52.8)$ & $57.49(57.4-57.6)$ & $63.22(61.7-64.7)$ \\
\hline \multicolumn{4}{|l|}{ Age } \\
\hline $18-44$ & $13.64(13.1-14.2)$ & $40.1(39.7-40.5)$ & $13.25(12.3-14.3)$ \\
\hline $45-64$ & $45.71(45-46.5)$ & $24.73(24.6-24.9)$ & $51.61(50.1-53.1)$ \\
\hline $65-84$ & $38(37.2-38.8)$ & $26.97(26.8-27.2)$ & $33.41(32.0-34.9)$ \\
\hline$>85$ & $2.65(2.4-2.9)$ & $8.2(8.1-8.3)$ & $1.73(1.4-2.2)$ \\
\hline \multicolumn{4}{|l|}{ Race } \\
\hline White & $83.14(82.2-84.1)$ & $65.91(65.3-66.5)$ & $86.86(85.6-88.1)$ \\
\hline Black & $7.06(6.6-7.5)$ & $14.98(14.6-15.4)$ & $4.86(4.2-5.6)$ \\
\hline Hispanic & $6.37(5.7-7.1)$ & $12.19(11.7-12.7)$ & $5.93(5.0-7.0)$ \\
\hline Asian/Pacific Islander & $0.92(0.8-1.1)$ & $2.77(2.7-2.9)$ & $0.54(0.34-0.88)$ \\
\hline Native American & $0.45(0.4-0.6)$ & $0.65(0.6-0.7)$ & $0.47(0.3-0.72)$ \\
\hline Other & $2.05(1.8-2.4)$ & $3.49(3.3-3.7)$ & $1.33(1.0-1.8)$ \\
\hline \multicolumn{4}{|l|}{ Location } \\
\hline Urban & $94.12(92.8-95.2)$ & $89.37(89.0-89.7)$ & $93.58(92.1-94.8)$ \\
\hline Rural & $5.88(4.8-7.2)$ & $10.63(10.3-11.0)$ & $6.42(5.2-7.9)$ \\
\hline
\end{tabular}

Results listed represent the average proportion per year as a percentage with $95 \%$ confidence interval 


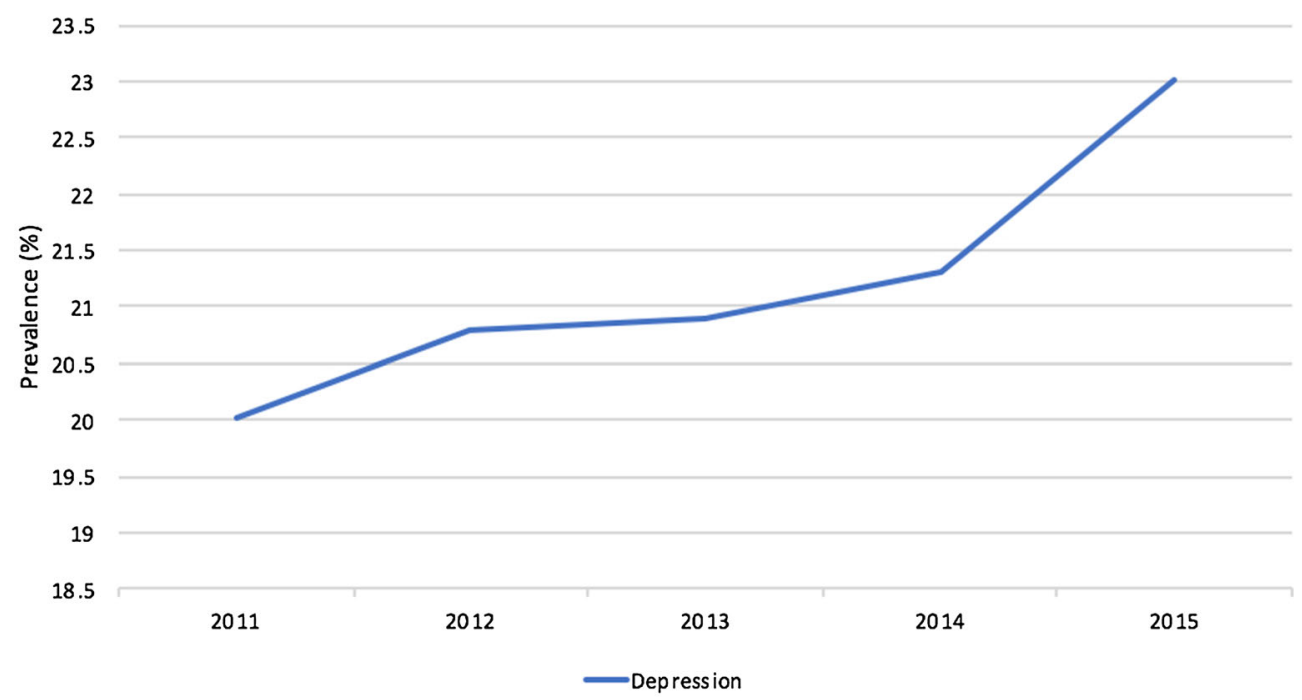

Fig. 1 Trend in prevalence of co-morbid depression among patients hospitalized for failed back syndrome, 2011-2015

\section{Depression Trends amongst Different Age Groups, Race, and Gender}

Most of the patients with depression were between ages 45 and $64(51.6 \%)$ and 65 and 84 years (33.4\%) from 2011 to 2015 (Fig. 2). These age groups had a significantly higher depression rate compared to patients without depression $(p<0.001)$. Significantly lower depression rates were seen amongst patients with ages over 85 and patients within age groups 18-44 (Table 1). Overall, the highest period prevalence of depression between 2011 and 2015 was observed amongst white patients followed by Native Americans (Fig. 3). This period prevalence was $21.98 \%$ and $20.88 \%$ for

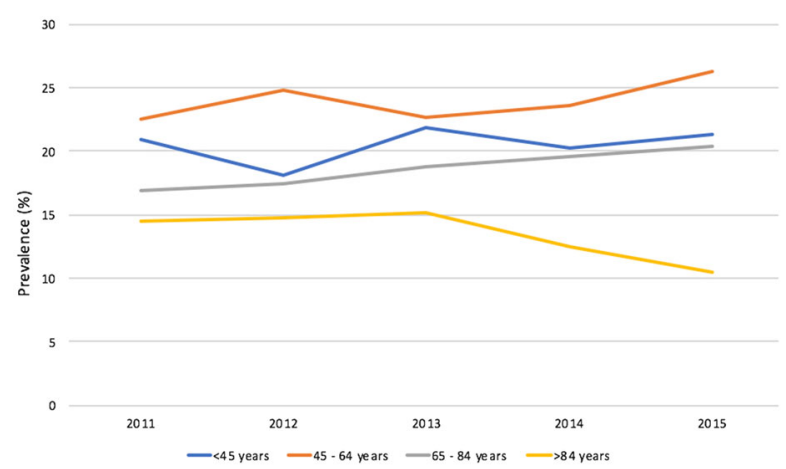

Fig. 2 Trend of depression prevalence in patients admitted for failed back syndrome by age group, 2011-2015 whites and Native Americans, respectively. Native Americans were observed to have the highest depression prevalence in 2011 and 2012. They also had the lowest depression prevalence in 2015 (Fig. 2). Hispanics accounted for the third majority of racial group with depression (19.3\%). Amongst white patients, the rate of depression was a significantly higher rate compared to white patients without depression $(p<0.001)$ (Table 1$)$. Interestingly, other ethnic groups had significantly lower rates of depression compared to similar ethic groups without depression (Table 1). From 2011 to 2015, the proportion of females with depression was higher compared to males; $25.7 \%$ of female patients had co-morbid

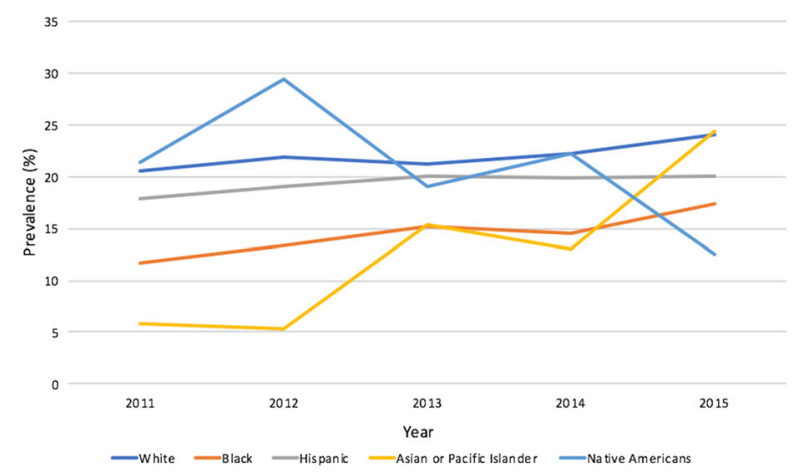

Fig. 3 Trend of co-morbid depression in patents admitted for failed back syndrome by race, 2011-2015 


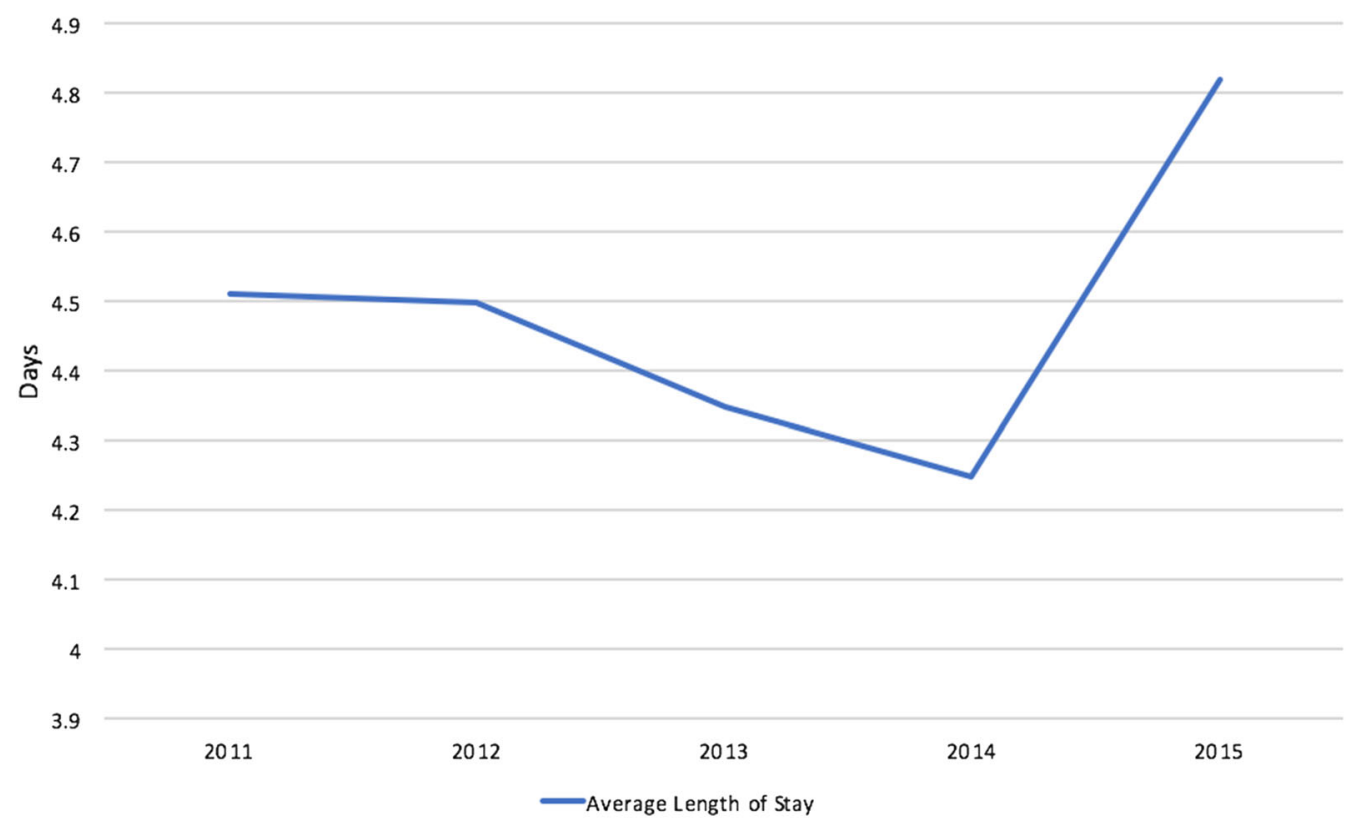

Fig. 4 Trend of average length of stay among patients admitted for failed back syndrome with co-morbid depression, 2011-2015

depression compared to $16.3 \%$ of males. Females had a significantly higher rate of comorbid depression compared to females without depression (Table 1).

\section{Depression Trends and Healthcare Utilization}

\section{Length of Stay and Number of Inpatient Procedures}

Over the 5-year period, the average length of stay for FBSS patients with co-morbid depression was 4.47 days (95\% CI 4.32-4.62 days). The mean LOS was stable from 2011 to 2014, ranging from 4.3 to 4.5 days (Fig. 4). The most dramatic increase in LOS over a single year was from 4.3 days (95\% CI $4-4.5$ days) in 2014 to 4.8 days (95\% CI 4.5-5.1 days) in 2015. The average number of procedures performed on patients with depression, over the 5-year period was 3.79 (95\% CI 3.67-3.92). The yearly number of procedures was fairly stable.

\section{Direct Hospital Cost}

The mean total hospital cost (mean $\$ 89,156$, 95\% CI \$84,821-\$93,491) for FBSS patients with co-morbid depression remained relatively stable over the 5-year period from 2011 to 2015 (Fig. 5). The mean total hospital cost in 2015 (mean $\$ 94,762 ; 95 \%$ CI $\$ 85,955-\$ 103,569$ ) was not significantly different from the mean total hospital cost in 2011 (mean \$93,939; 95\% CI $\$ 80,064-\$ 107,815)$. The most dramatic increase in mean total hospital cost for FBSS patients with co-morbid depression was from $\$ 82,603$ (95\% CI $\$ 75,127-\$ 90,079)$ in 2012 to $\$ 91,824$ $(95 \%$ CI $\$ 80,064-\$ 107,815)$ in 2013 . The total

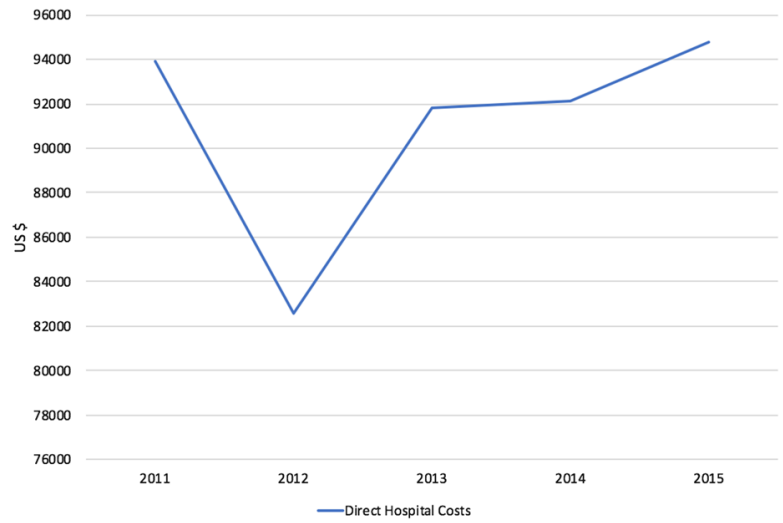

Fig. 5 Trend of total hospital cost among patients admitted for failed back syndrome with co-morbid depression, 2011-2015 


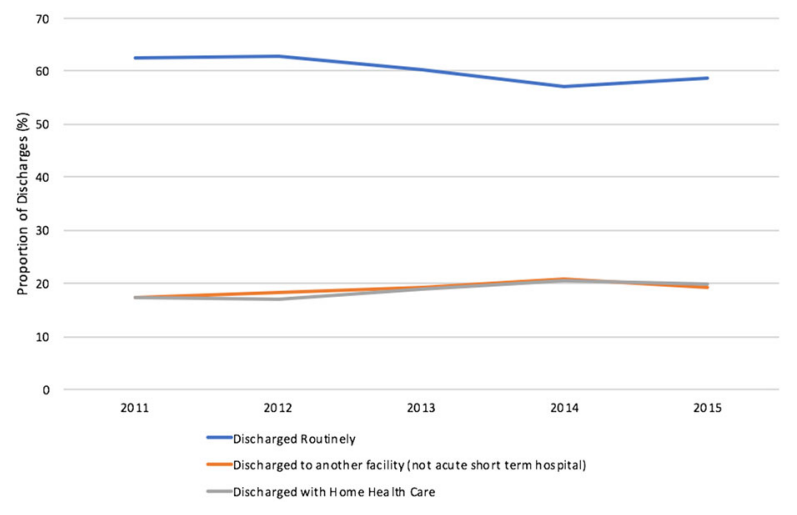

Fig. 6 Trend of discharges by disposition among patients admitted for failed back syndrome with co-morbid depression, 2011-2015

hospital cost was relatively stable over the 5-year period with a dip in 2012 .

\section{Discharge Locations}

Over the 5-year period, the majority of discharge dispositions for FBSS patients with comorbid depression were routine. FBSS patients with co-morbid depression were routinely discharged $57.1-62.9 \%$ of the time. Less commonly, these patients were either discharged to another facility (not including an acute shortterm hospital) or discharged to home with home healthcare (Fig. 6).

\section{DISCUSSION}

Our study is the first to investigate the characteristics of co-morbid depression in hospitalized patients with a diagnosis of FBSS. Our analysis demonstrates that the rate of co-morbid depression in hospitalized patients with FBSS increased from 20 to $23 \%$ over a 5 -year period, between 2011 and 2015. Epidemiologic studies indicate a lifetime prevalence of major depression of around $17 \%$ in the general population $[16,17]$. The prevalence of depression in patients with chronic back pain has previously been estimated to be 2-3 times greater than in the general population [18]. Depression is also thought to be present in one-third of the patients who ultimately undergo spine surgery, significantly increasing the risk of developing
FBSS and persistent chronic pain thereafter [19]. It is not surprising then that the FBSS patient population has traditionally been described as carrying a high rate of co-morbid depression. In 1988, Long et al. reported that 67 out of their 78 (85.8\%) patients with FBSS suffered from reactive depression [20]. More recently, the PROCESS trial reported a figure of $50 \%$ of FBSS patients suffering from depression. It is important to note that demographic data surrounding the FBSS patient population continues to be thin, which likely explains the wide discrepancy in figures reported across different studies. Similar to other studies, our data suggest that the rates of FBSS in hospitalized patients with depression is higher compared to hospitalized patients without depression. Although our investigation lacks the robustness of a prospective study, it draws from one of the largest patient datasets currently available and shows a stable prevalence rate over a 5-year period.

One aspect that the NIS dataset does not capture is the severity of conditions. It is plausible that although the rates of diagnosed clinical depression in the hospitalized FBSS population are relatively low, the severity of this co-morbidity could presumably be higher as compared to the general, or even hospitalized, populations. Studies assessing the severity of depressive symptoms in the FBSS patient population have generally reported higher scores on inventory indices compared to controls $[8,21]$. There is evidence to suggest that psychosocial factors play a vital role in the outcomes of patients undergoing spinal surgery. Depression, in particular, has been associated with poorer surgical outcomes and decreased rehabilitative improvement. In a retrospective cohort of workers compensation subjects, preoperative depression was found to be a significant negative predictor of return to work following fusion [12]. Similarly, in patients undergoing back surgery for chronic pain, depression was found to be associated with increased postoperative pain, increased severity of symptoms, decreased walking capacity, and less overall satisfaction with their outcomes [22-25]. Based on our analysis and others', it follows that there may exist a relatively smaller subset of patients with FBSS and severe co- 
morbid depression, which may benefit from more aggressive psychiatric therapy compared to FBSS patients without depression.

The treatment and management of low back pain creates a tremendous economic burden in the United States, estimated to range from 19.6 to 118.8 billion in total cost [26]. Furthermore, in a retrospective analysis of 211,551 patients comparing their individual direct costs, patients who underwent surgery for low back pain incurred $\$ 33,931$ compared to nonsurgical patients with low back pain who incurred $\$ 7211$ [27]. Interestingly, the length of hospital stay and direct hospital cost in the subset of patients we studied trended upwards during our analysis period. This is despite the fact that the rates of our studied conditions remained relatively stable during the study period. Since the number of procedures performed was also relatively stable, it is possible that the LOS is the primary driver of expenditures in this population in hospital settings. This could be due to a host of reasons, including but not limited to increasing severity of other co-morbidities, increasing age, increasing severity of neuropathic pain secondary to FBSS, etc. Additional studies are clearly needed to further delineate the factors underlying the rise in LOS and cost in the FBSS population.

In terms of demographics, amongst patients with FBSS, female gender, higher age, obesity, number of spine surgeries, multiple fused spinal levels, smoking status, and high usage of analgesics negatively influence recovery [28, 29]. Most of these factors have been implicated in the etiology of depression in this patient population as well. Our findings suggest a preponderance of co-morbid depression in FBSS in the older female Caucasian group, with the highest rates found in white females aged 45-64. More data confirming these demographic trends could be helpful in stratifying at-risk patients both pre- and post-surgery to help improve both short-term recovery and long-term outcomes following spine surgery.

There are several limitations to our study. First, as noted earlier, the NIS database does not contain variables that can evaluate disease severity. This information, such as the severity of depression and its relationship to worsening chronic pain and other psychopathologies, was not available for analysis. Second, the NIS database does not include detailed co-morbid depressionrelated cost information and only reports total hospital charges. This unfortunately makes specific cost analysis impossible, including ICU admission cost, cost of administered anesthesia, procedure room charges, and postoperative charges. Third, healthcare utilization outcomes available for analysis in this study may not be directly related to co-morbid depression. They could be influenced by multiple factors such as payer status and social factors. Fourth, the NIS database is highly dependent on the selection and reported accuracy of the appropriate diagnostic ICD codes [30]. For example, the rise in co-morbid depression may reflect coding artifact or may result from the implementation and rapid adoption of new ICD-9 codes.

\section{CONCLUSIONS}

The occurrence of co-morbid depression in hospitalized patients with FBSS is estimated to have increased from 20 to $23 \%$ and this prevalence is higher than the general population. The direct hospital costs and length of stay remained relatively stable, however, the number of inpatient procedures performed trended upwards. The exact etiology for this increase in depression prevalence is unknown. Additional studies are needed to shed further insight into the demographic trends and the cost make-up underlying care of patients with co-morbid depression and FBSS.

\section{ACKNOWLEDGEMENTS}

Funding. No funding or sponsorship was received for this study or publication of this article.

Authorship. All named authors meet the International Committee of Medical Journal Editors (ICMJE) criteria for authorship for this article, take responsibility for the integrity of the work as a whole, and have given their approval for this version to be published. 
Author contributions. All authors critically revised the manuscript, interpreted the results, and performed a critical review of the manuscript for intellectual content.

Disclosures. Vwaire Orhurhu, Ivan Urits, Mayowa Olusunmade, Khurram Owais, Mark Jones, Annemarie Galasso, Mariam Salisu Orhurhu, and Issa Mohammed have nothing to disclose.

Compliance with ethics guidelines. The NIS dataset does not directly involve "human subjects" as defined by federal regulations and guidance (https://www.hhs.gov/ohrp/ regulations-and-policy/regulations/commonrule/index.html). Thus, all procedures performed were in accordance with the ethical standards of the institutional and/or national research committee and with the 1964 Helsinki Declaration and its later amendments or comparable ethical standards.

Data availability. The dataset analyzed during the current study are available in the NIS repository by the Agency for Healthcare Research and Quality, http://www.hcup-us. ahrq.gov.

Open Access. This article is distributed under the terms of the Creative Commons Attribution-NonCommercial 4.0 International License (http://creativecommons.org/licenses/ by-nc/4.0/), which permits any noncommercial use, distribution, and reproduction in any medium, provided you give appropriate credit to the original author(s) and the source, provide a link to the Creative Commons license, and indicate if changes were made.

\section{REFERENCES}

1. Chan C. Failed back surgery syndrome-review article. Pain Med. 2011;12:577-606.

2. Hoy D, March L, Brooks P, Blyth F, Woolf A, Bain C, et al. The global burden of low back pain: estimates from the Global Burden of Disease 2010 study. Ann Rheum Dis. 2014;73(6):968-74.
3. Smith M, Davis MA, Stano M, Whedon JM. Aging baby boomers and the rising cost of chronic back pain: secular trend analysis of longitudinal medical expenditures panel survey data for years 2000 to 2007. J Manip Physiol Ther. 2013;36(1):2-11.

4. Frymoyer JW, Catsbaril W. An overview of the incidences and costs of low-back-pain. Orthop Clin N Am. 1991;22(2):263-71.

5. Rajaee SS, Bae HW, Kanim LE, Delamarter RB. Spinal fusion in the United States: analysis of trends from 1998 to 2008. Spine (Phila Pa 1976). 2012;37(1):67-76.

6. Deyo RA, Gray DT, Kreuter W, Mirza S, Martin BI. United States trends in lumbar fusion surgery for degenerative conditions. Spine (Phila Pa 1976). 2005;30(12):1441-5.

7. Slipman $\mathrm{CW}$, Shin $\mathrm{CH}$, Patel RK, Isaac Z, Huston CW, Lipetz JS, et al. Etiologies of failed back surgery syndrome. Pain Med. 2002;3(3):200-14.

8. Sahin N, Karahan AY, Devrimsel G, Gezer IA. Comparison among pain, depression, and quality of life in cases with failed back surgery syndrome and non-specific chronic back pain. J Phys Ther Sci. 2017;29(5):891-5.

9. Follett AK, Dirks AB. Etiology and evaluation of the failed back surgery syndrome. Neurosurg Q. 1993;3(1):40.

10. Nachemson AL. Evaluation of results in lumbar spine surgery. Acta Orthop Scand. 1993;64 (Supp 251):130-3.

11. Thomson S, Jacques L. Demographic characteristics of patients with severe neuropathic pain secondary to failed back surgery syndrome. Pain Pract. 2009;9(3):206-15.

12. Anderson JT, Haas AR, Percy R, Woods ST, Ahn UM, Ahn NU. Clinical depression is a strong predictor of poor lumbar fusion outcomes among workers' compensation subjects. Spine (Phila Pa 1976). 2015;40(10):748-56.

13. AHRQ. HCUP nationwide inpatient sample (NIS). Healthcare cost and utilization project (HCUP). Rockville.

14. Healthcare Cost and Utilization Project (HCUP). Introduction to the nationwide inpatient sample (NIS). Agency Healthc Res Qual. 2010;2012:2014.

15. Bohl DD, Russo GS, Basques BA, Golinvaux NS, Fu $\mathrm{MC}$, Long WD, et al. Variations in data collection methods between national databases affect study results: a comparison of the nationwide inpatient sample and national surgical quality improvement 
program databases for lumbar spine fusion procedures. J Bone Jt Surg Am. 2014;96(23):e193.

16. Andrade L, Caraveo-Anduaga JJ, Berglund P, Bijl RV, De Graaf R, Vollebergh W, et al. The epidemiology of major depressive episodes: results from the International Consortium of Psychiatric Epidemiology (ICPE) surveys. Int J Methods Psychiatr Res. 2003;12(1):3-21.

17. Kessler RC, Berglund P, Demler O, Jin R, Merikangas $\mathrm{KR}$, Walters EE. Lifetime prevalence and age-of-onset distributions of DSM-IV disorders in the National Comorbidity Survey Replication. Arch Gen Psychiatry. 2005;62(June):593-602.

18. Moore JE. Chronic low back pain and psychosocial issues. Phys Med Rehabil Clin N Am. 2010;21(4):801-15.

19. Schofferman J, Reynolds J, Herzog R, Covington E, Dreyfuss P, O'Neill C. Failed back surgery: etiology and diagnostic evaluation. Spine J. 2003;3(5):400-3.

20. Long DM, Filtzer DL, BenDebba M, Hendler NH. Clinical features of the failed-back syndrome. J Neurosurg. 1988;69(1):61-71.

21. Yalbuzdag SA, Erol AM, Sengul I, Celik C, Solum S, Adilay HU, et al. Temperament and character profile in failed back surgery syndrome: a cross-sectional clinical study. Turk Neurosurg. 2016;26(6):912-7.

22. Sinikallio S, Aalto T, Airaksinen O, Lehto SM, Kröger $\mathrm{H}$, Viinamäki H. Depression is associated with a poorer outcome of lumbar spinal stenosis surgery: A two-year prospective follow-up study. Spine (Phila Pa 1976). 2011;36(8):677-82.

23. Zong Y, Xue Y, Zhao Y, Ding H, He D, Li Z, et al. Depression contributed an unsatisfactory surgery outcome among the posterior decompression of the cervical spondylotic myelopathy patients: a prospective clinical study. Neurol Sci. 2014;35(9):1373-9.

24. Strøm J, Bjerrum MB, Nielsen CV, Thisted CN, Nielsen TL, Laursen M, et al. Anxiety and depression in spine surgery-a systematic integrative review. Spine J. 2018;18(7):1272-85.

25. Dorow M, Löbner M, Stein J, Konnopka A, Meisel HJ, Günther L, et al. Risk factors for postoperative pain intensity in patients undergoing lumbar disc surgery: a systematic review. PLoS One. 2017;12(1):1-24.

26. Dagenais S, Caro J, Haldeman S. A systematic review of low back pain cost of illness studies in the United States and internationally. Spine J. 2008;8(1):8-20.

27. Ivanova JI, Birnbaum HG, Schiller M, Kantor E, Johnstone BM, Swindle RW. Real-world practice patterns, health-care utilization, and costs in patients with low back pain: the long road to guideline-concordant care. Spine J. 2011;11(7):622-32.

28. Boswell MV, Shah RV, Everett CR, Sehgal N, McKenzie-Brown AM, Abdi S, et al. Interventional techniques in the management of chronic spinal pain: evidence-based practice guidelines. Pain Physician. 2005;8(1):1-47.

29. Arts MP, Kols NI, Onderwater SM, Peul WC. Clinical outcome of instrumented fusion for the treatment of failed back surgery syndrome: a case series of 100 patients. Acta Neurochir (Wien). 2012;154(7):1213-7.

30. Berthelsen CL. Evaluation of coding data quality of the HCUP national inpatient sample. Top Health Inf Manage. 2000;21(2):10-23. 